\title{
Integration of a Dolomite Risk Management Programme in Local Governance in South Africa: Tlokwe City Council
}

\author{
Abraham Stephanus Potgieter ${ }^{1}$, Stephanus Johannes Pretorius ${ }^{1}$, \\ Izak Jacobus Van Der Walt ${ }^{2}$ \\ ${ }^{1}$ AGES North West, Potchefstroom, South Africa \\ ${ }^{2}$ School of Environmental Sciences, North-West University, Potchefstroom, South Africa \\ Email: spotgieter@ages-group.com
}

Received 22 April 2016; accepted 13 June 2016; published 16 June 2016

Copyright (C) 2016 by authors and Scientific Research Publishing Inc.

This work is licensed under the Creative Commons Attribution International License (CC BY). http://creativecommons.org/licenses/by/4.0/

(c) (7) Open Access

\begin{abstract}
Development on dolomite poses a risk to people and their assets living on it. Although development in the Tlokwe City Council (TCC) broadly took cognisance of the presence of dolomite, some parts of the township had been developed on dolomite. Therefore, since the Council is accountable for safe development within its jurisdiction, a Dolomite Risk Management Programme (DRMPr) should be put in place according to prevailing legislation, standards and guidelines. For long-term mitigation measures to be implemented successfully, the DRMPr should be integrated and aligned within the existing structure and processes of the Council. This exercise is described, with some challenges identified and recommendations made, for consideration in the same or similar programmes in future.
\end{abstract}

\section{Keywords}

Dolomite, Hazard, Development, Risk, Management, Mitigation, Strategy, Plan, Programme, Integrate, Implement

\section{Introduction}

Dolomite is a type of rock with a dishomogeneous weathering character with softer or more weathered material dissolving relatively easily in water resulting in a karst landscape with potential sub-surface cavities [1] [2]. This weathered material can be mobilised or eroded by leaking wet services or through groundwater level drawdown which then causes sinkholes to occur on the surface, resulting in damage to buildings and infrastructure, injury 
or even loss of life [3]-[5].

Dolomite is a world-wide phenomenon and South Africa seems to be ahead of its counterparts in terms of the management of development on dolomite land [2] [6]. Although the inherent character as well as the effect of development on dolomite is well-known and researched, the pro-active risk management of development on dolomite is encountered very seldom, both in developed and developing countries [4].

Development in the Tlokwe City Council (Tlokwe City Council) started before the dangers associated with development on dolomite were fully understood [7]. Although development broadly took cognisance of the presence of dolomite in later years, some parts of the townships were nonetheless developed on dolomite, partly due to planners being not aware of dolomite, but also because the development guidelines and standards for development on dolomite only developed over time.

This reality necessitated the development of a Dolomite Risk Management Programme for the Tlokwe local authority in the North West Province, South Africa.

A Dolomite Risk Management Programme (DRMPr) is a tool to manage the risks associated with development on dolomite, with the main objective being to protect the people living on it and their investment [8]. A DRMPr is a process where the context is established, hazards identified, risks analysed, evaluated and mitigated and continuously monitored and reviewed [7].

The aim of this research paper is to describe the development and integration of an effective framework for a DRMPr within local government in South Africa, with specific reference to the Tlokwe City Council.

\section{The Framework for Effective Dolomite Risk Management}

The legislation in South Africa, from as broad as the Constitution (108 of 1996) [9], through the Municipal Systems Act (32 of 2000) [10] and up to the Disaster Management Act (57 of 2002) [11], to name but a few, in combination with the relevant and specific standards and guidelines such as the SANS 1936 (2012) [8], gives a well-defined framework for any development on dolomite, which it would be negligent to ignore. Although the prevailing standards mainly focus on greenfields development, existing development and infrastructure on dolomite pose some additional challenges in order to manage the risk towards being tolerable.

Legislation forms the common ground from which actions and cooperation between various role-players can be derived to ensure a free, equal, transparent and humane society which forms the foundation of the Constitution of the Republic of South Africa (108 of 1996) [9] (hereafter the Constitution). This culminates in the Bill of Human Rights in the Constitution that provides all South Africans with the right to equality, life, freedom, privacy, labour relations, environment, association, property, physical body, health, etc. The purpose of this paper is therefore to highlight the human/social and technical geological issues related to dolomite from a legal perspective [12].

Subsequent to the law, it is required to also explain the risk and liability associated with non-compliance with these legal requirements which are the real issue in the implementation and execution of any risk-based strategy and plan. Any alignments associated with Dolomite Risk Management as defined by the SANS 1936 (2012) [8] standards and other management plans/systems required (as defined by other legislation) are also highlighted. The SANS 1936 (2012) [8] standards forms the basis for the requirements for the sustainable management and development of dolomite land.

The objective of all four of the SANS 1936 standards regarding the development on dolomite land-as described in each of the introductory sections-is to set requirements for the development of dolomite land in order to ensure that people live and work in an environment that is seen by society to be acceptably safe, where loss of assets is within tolerable limits, and where cost-effective and sustainable land usage is achieved. This statement is aligned with the sections (i.e. Ss 24 and 152 (1) (d)) in the Constitution that provide for everyone to have the right and local government with the obligation to have/promote a safe and healthy environment for everyone.

Sinkholes are in the unique position of being both a natural and potentially man-induced disaster. It is also very difficult to predict the exact time and place of the occurrence of a sinkhole event [12]. While natural disasters are unpreventable, man-made/induced disasters can be prevented by appropriate strategies, plans and actions taken to reduce vulnerability to risk as defined in both SANS 1936 (2012) [8] and the Disaster Management Act 57 of 2002. Therefore any development on dolomite land can pose a potential disaster risk and liability to the local authority, land owner, developer and occupants of buildings on dolomite land-especially if not properly managed. In cases where there is a potential of adversely affecting the community due to the risk arising from 
natural or man-induced activities, transparency and sharing of information are required, though it must be done in a sensible manner (Constitution, Section 195 (1) (g) [9] and SANS 1936, Section 4.4.6, 2012 [8]).

The need to protect and promote social and economic development and the need to establish suitable institutions in order to achieve the purpose of these acts are fundamental to this legislative framework. There exists, however, a gap in the municipal by-laws and their lack of integration with issues concerning dolomite. This lack is enhanced by existing and future land-use planning and infrastructure on dolomite and compliance with all the related NHBRC's GHBM 2014 requirements. It is also recommended to integrate or align where relevant frameworks, plans and procedures for more effective use of resources-especially between Disaster Risk Management and dolomite related strategies and plans.

The risk involved for legal non-compliance is ultimately on development that has taken place on nonecumene land, which should otherwise have remained unoccupied, or designed and developed according to the national standards. The legal risk of developing on dolomite land can range from being accountable to justify actions or decisions made wrongly and knowingly to accepting legal responsibility for loss of life. Therefore the risk needs to be managed and the responsibility thereof lies with the accountable persons or officials who need to be assisted and empowered in this regard.

\section{Development of a DRMPr}

A phased DRMPr for the Tlokwe City Council was introduced in 2009. This programme consisted of four processes aligned and implemented in three phases over a period of five years. Phase A had a focus on hazard identification and status assessment (i.e. basic process), Phase B on risk analysis and evaluation (i.e. research process) and lastly Phase $\mathrm{C}$ had a focus on risk management process as well as mitigation, monitoring and the review process (Figure 1).

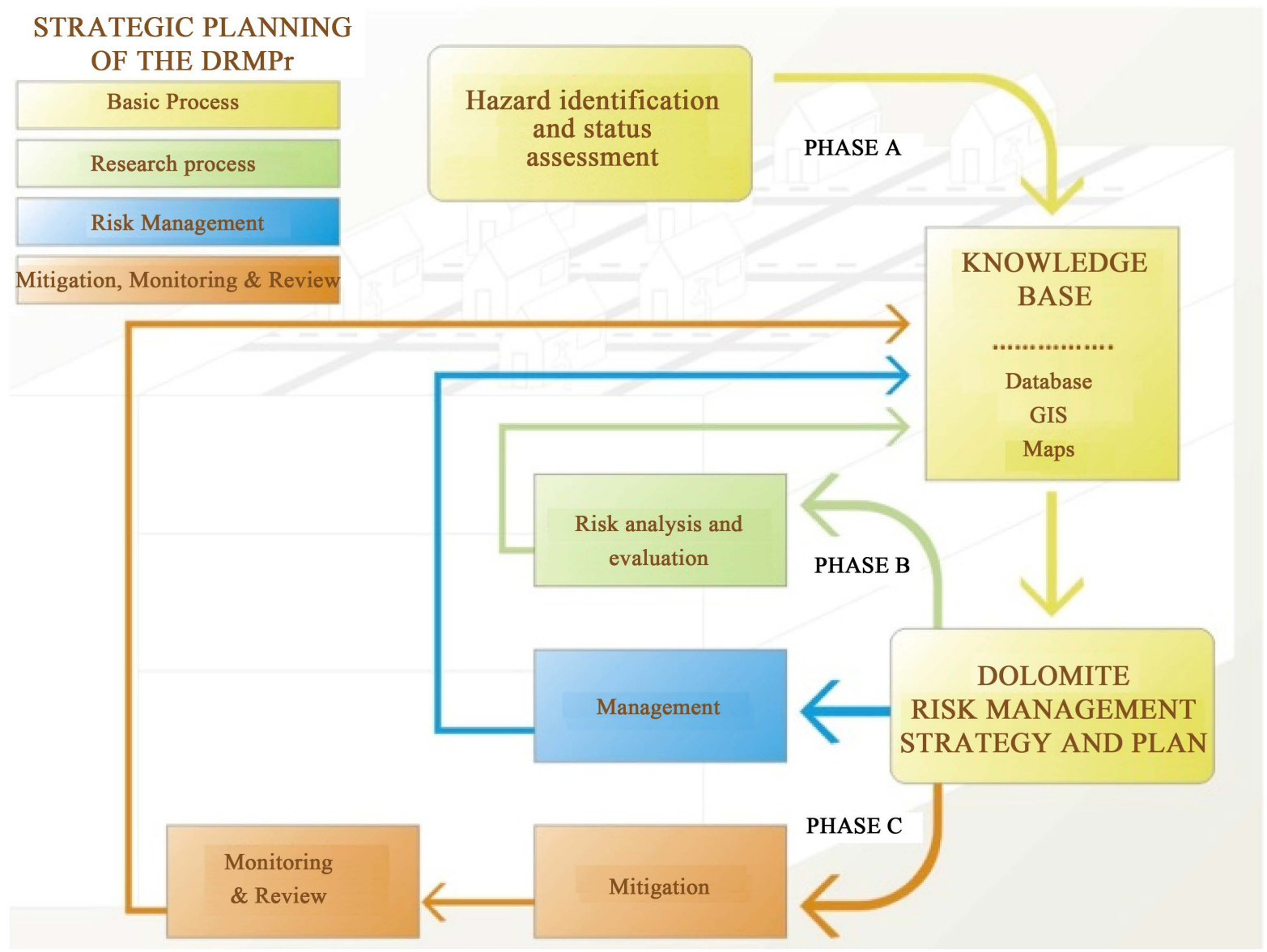

Figure 1. Strategic planning of the DRMPr: Components and processing [7]. 


\subsection{Hazard Identification and Status Assessment (Phase A)}

The hazard identification and status assessment identified two main factors that contribute to the risk with regards to development on dolomite. The first factor is related to the physical environment, such as geology, geohydrology and engineering geology. The anthropogenic environment is the second factor, which includes existing infrastructure and development, land use planning and the social structure within the study area [13] [14].

The exact extent and location of dolomite were determined and then, based on all available existing information, a prioritised risk zoning of the area was compiled in order to present the indicated inherent hazard, based on the probable occurrence of dolomite [15]-[17]. The geohydrological investigation revealed that there is no significant large-scale groundwater abstraction in the direct vicinity of the study area and that the average groundwater level is at a depth of less than $30 \mathrm{~m}$ from the surface [15]. The geotechnical properties were found to vary, but necessitated further research in order to be able to measure the risk based on inherent hazard classes, which was done during Phase B.

The initial investigation to determine the risk associated with existing infrastructure revealed that most of the sub-surface water-bearing infrastructure is old and not on the current standards for such development on dolomite. Some of the very old infrastructure has been assumed to be leaking extensively [15]. The existing land use was identified as mostly high-density residential development [15], with the residents as well as officials and politicians of the local municipality largely oblivious of the presence of and risk associated with development on dolomite [15]. Most of the residents were found to be very vulnerable as they are mostly from a low-income bracket. A preliminary risk assessment was done where the two main contributing factors were weighed and combined into one final disaster risk score, resulting in sixteen different focus areas which were prioritised for further research during the next phase.

\subsection{Risk Analysis and Evaluation (Phase B)}

An integrated dolomite stability investigation formed the basis for further risk management measures. This investigation entailed new gravity surveys in areas with no information, drilling of 255 new boreholes and the integration of the new information with existing information (i.e. previous gravity surveys and 182 existing boreholes) in order to compile a detailed geotechnical model with resultant inherent hazard class zones with associated general hazard characterisation [18]. The results of this dolomite stability investigation indicated that the underlying dolomite strata exhibit adverse geotechnical characteristics requiring the implementation of specific design and/or precautionary measures to reduce the risk of structural damage and loss of life. The inherent hazard class zones were grouped together as low, medium and high, and then further aligned into five general Dolomite Risk Management Areas (DRMAs). The DRMAs were aligned with stand boundaries to prevent any confusion for landowners.

The integrated groundwater-surface water assessment concluded that there is an indicated interaction between groundwater and surface water in the regional study area [19]. There is also an inferred correlation between groundwater levels and a horizontally orientated weathered and cavernous zone, with groundwater levels either closely related to the cavities or occurring in close proximity of the cavernous zone. The groundwater levels fluctuated on average by $0.25 \mathrm{~m}$ since 2000 , with a maximum drop of $1.38 \mathrm{~m}$ recorded in areas affected by pumping, and a similar increase in areas with artificial ingress. Although various groundwater uses were identified, no evidence of legally allocated water use rights was found. Several uses were, however, registered with the Welgegund Groundwater Management Area to the north of the focus study area in Tlokwe City Council. Although all existing information related to the groundwater regime was studied, the dolomitic compartments and the effect of old mining activity would require further detailed research. The results of the geohydrological assessment indicate that both groundwater and surface water need to be managed in an integrated manner. For this reason, Water Management Areas were identified with specific requirements set for each of them.

An anthropogenic hazard assessment of the internal wet services (water reticulation and sewer), storm-water and roads was done, which included field inspection and verification of services. The study area was ranked from having a $0 \%$ deviation from an ideal design on dolomite right through to $100 \%$ deviation indicating gross non-compliance [20]. Specific mitigation measures were proposed, as well as conceptual implementation plans, technical requirements for design criteria, an upgrade philosophy, proposed costing model, envisaged projects and operation and maintenance guidelines.

Another important factor that was assessed is the existing residential development on dolomite. The actual 
densities were measured against the guidelines in SANS and combined with the DRMAs in order to get to specific Land Use Management Areas (LUMAs) to address management of the land uses and housing. A total of 5 693 stands are affected by dolomite [21].

The social awareness programme was generally accepted positively by the affected community. During the risk-assessment phase, the awareness programme focused mainly on baseline awareness, community liaison during drilling, focussed awareness through door-to-door visits and several other means to reach all spheres of the affected community and municipality. It was found that the vulnerability of the households coinciding with technical research findings and lack of awareness creates a very dangerous situation. A framework towards future social awareness was compiled for the long term as well as the immediate future [7].

Based primarily on the inherent character of the dolomite, the study area was prioritised into 33 areas for further mitigation, management and monitoring. The overall conclusion from this phase was that although the geological conditions were in general and in most areas not favourable for the development that has already taken place, the groundwater regime was relatively stable and can be managed. Furthermore, although the services are to a very large extent non-compliant with dolomite standards, they can be upgraded to the desired level and therefore also managed towards a more tolerable situation.

\subsection{Management, Mitigation, Monitoring and Review}

Although management, mitigation, monitoring and review were a main focus in Phase C, some elements had already been attended to during Phase B in order to reduce the risk where necessary. The three main areas that received attention were the subsidence features in Sarafina and Kanana, and the imminent danger of collapse of the Ikageng-West Reservoirs. Groundwater use and levels and land use were monitored according to monitoring priorities and schedules [7].

\subsection{Dolomite Risk Management Strategy and Plan}

The findings from Phase B culminated in a Dolomite Risk Management Strategy and Plan (DRMS and DRMP). The DRMS is defined as the strategic framework and enforcing mechanism for a DRMP that allow the roll out of a Dolomite Risk Management Programme (DRMPr) in a planned and orderly manner [7].

Perhaps the most defining decision in the strategy was to rather manage and mitigate the risk within the existing development than resettle all affected households. This resulted in the prioritisation of mitigation measures, with socio-economic and engineering aspects as top priorities for further action. A dolomite risk-management structure was developed, defining titles and roles for each member. Specific strategies were developed for every main topic from a regulatory, institutional and community point of view [7].

The DRMS formed the basis for the DRMP which includes detailed recommendations on how to further assess, monitor, manage and mitigate risk within the different facets such as the socio-economic, land use, geoenvironmental and engineering ones. The relevant departments and role-players in the Tlokwe City Council were identified and implementation timeframes set. This all culminated in a prioritised framework for further implementation, indicating the relevant topic, aspect or project, mitigation focus topics, responsible entity, estimated cost and time span [7].

\section{Implementation and Integration of a DRMPr}

Three main role-players were identified that had to be aligned: the legal (including the regulatory authority, relevant acts, regulations, standards and guidelines), the institutional (for example the local or implementing authority or organisation), and the social (as the affected community). In the case of the Tlokwe City Council, the legal component is the Council-approved and adopted DRMS based on the prevailing SANS 1936 (2012) [8], the institutional component was the Tlokwe City Council itself, and the social component was the community affected by the dolomite reality. The aim was to align these three role-players with each other.

The Tlokwe City Council officially adopted the DRMS in 2014, which then introduced the third phase of the DRMPr where the strategy had to be implemented. An implementation plan was developed mainly based on the approved DRMS, DRMP, council resolution, steering committee meetings and the annual internal review report. The outcome of this exercise resulted in four main focus areas for integration and alignment as part of Phase C1, before the implementation of mitigation measures could occur as Phase C2: 
- Implementation and management of the DRMS and DRMP;

- Facilitation and promotion of institutional integration and alignment;

- Emergency events or incidents; and

- Continuous specialist advisor input.

All actions were prioritised in order to address "quick wins" first, and tasks were allocated to specific role players and responsible persons within time frames and budgets. Skills transfer and training of the Tlokwe City Council were an on-going focus area throughout the programme.

A dolomite help desk was established primarily to promote communication between the Tlokwe City Council, the community and AGES. It is also responsible for the GIS system and alignment of all processes.

The DRMPr had to be integrated within existing processes in each relevant department in the Tlokwe City Council. Procedures were developed in the building control office for building enquiries, in the town-planning office for land use change and rezoning and in the human settlement office for alignment between provincial and local housing projects. Infrastructure project processes also had to be amended, in order to promote the necessary input towards dolomite design and construction criteria, with several "gates" identified for this purpose. Within the department of public safety, emergency contingency plans and resettlement action plans were developed for further implementation.

Not only were specific by-laws developed for dolomitic areas, but the dolomite reality was also aligned with existing by-laws such as for infrastructure and SPLUMA. The reality encountered in the Tlokwe City Council was subsequently used in discussions to update and amend the SANS 1936 (2012) [8] where relevant, and also reasonable as part of the activities of Work Group 3 for the 2017 release of the standard.

The community was continuously involved in and informed about progress, made aware of the risk and informed of specific actions to be taken in the event of an incident, based on the specific social awareness programme. A Dolomite Risk Communication Strategy was developed to ensure that the known risk was communicated to all identified stakeholders [22].

\section{Discussion of Results}

The research identified three main role-players in society, which are discussed separately in the following section.

\subsection{Legal}

- The existence and content of SANS 1936 (2012) [8] need to be made known to all organisations or institutions, as well as professional persons, such as geo-professionals, engineers, town planners, environmental practitioners, etc.

- The concept and content of risk management, as defined in SANS 1936 Part 4 (2012) [8], should be aligned as well as possible with existing methodologies, concepts, principles and definitions as internationally accepted in environmental as well as disaster management fields of practice and presented in existing SANS and ISO standards in order to prevent any confusion.

- Regulations, standards and guidelines need to include more detail on how to manage, mitigate and monitor historical or existing development on dolomite in order to obtain principles that are reasonable to implement, especially in poor and/or rural communities.

- Alternative solutions may have to be considered, especially in historically existing developments in vulnerable communities and smaller local authorities under severe financial strain. There may also develop a distinction between urban and rural development on dolomite, both for greenfield and infill or brownfield development. These may include alternative housing concepts, alternative designs for both new houses and extensions and back-yard dwellings, alternative supply and/or design for wet services and even township layouts, especially in scattered rural settings.

- An official national dolomite regulatory authority is yet to be established. The role of the Council for Geoscience should be defined in this light, as being both an unofficial regulating authority and a professional organisation rendering advice to clients creates confusion and issues with regards to independence. It may be considered that the regulating authority should reside under another department, such as Public Safety under the Disaster Management Act.

- The definition of competent persons as well as the responsible or liable persons may have to be reviewed. 
With a lack of clear guidelines for existing development on dolomite, a big responsibility resides with the competent person to make decisions from a professional point of view with often legal implications. The peer-review process may have to be pursued and enforced much more actively.

- Insurance on dolomite for both property owners and services needs urgent further attention. The argument is that if the insurance industry clearly understands the risk through a comprehensive DRMPr indicating exactly where the high, medium and low risk areas are, the relevant insurance cover can be prepared. This may have a secondary spin-off where the insurance industry may help to regulate and promote the development and implementation of management, mitigation and monitoring measures.

- Maximum alignment should take place among the different regulatory authorities with guidelines on development on dolomite such as the SANS, CGS, NHBRC and the DPW.

- Further research is deemed essential along the same lines as followed in this study towards the determination of risk, or a comprehensive disaster risk score. Both physical and anthropogenic factors play a major contributory role, and how each of these two factors is calculated is to be defined and quantified in an industry-wide accepted methodology. There may be three different versions based on the three typical stages in disaster management and as followed in this DRMPr, with a basic version as in Phase A, a more comprehensive version towards Phase B as more information becomes available, and a final version during Phase $\mathrm{C}$ which can also be used to quantify the final disaster risk score for an area, taking all factors into consideration. This can further be used to track progress once mitigation measures are implemented, therefore targets can be set and performance tracked. During this process, the contribution of professional or specialist judgement as well as the availability of existing data and information should be strongly considered to augment the usual modelling, based on probability theory. It should, however, be noted that a balance should be obtained between a highly mathematical calculation and sound professional judgement.

- In the light of the absence of any recent sinkholes with resultant legal cases to develop and refer to, it may at some stage be beneficial to several local authorities, especially when decisions have to be made on existing development on dolomite, to request a declaratory order from a competent court to clarify potential legal exposure on certain scenarios and decisions taken, or not taken.

\subsection{Institutional}

- A DRMPr should be designed with this end in mind (i.e. implementation) right from its inception.

- Better alignment between political and administrative sectors of local government should be encouraged. Although most likely adequately covered in existing legislation, it should be stated that both the Municipal Manager and the Executive Mayor are primarily responsible as the accounting officers in the accounting authority or organisation for dolomite risk management. Political instability and inconsistency, as well as a lack of political will, can negatively impact on dolomite risk management. A critical look may be necessary on how government is structured to deal with disaster or dolomite risk and how current roles and responsibilities tie up with that of a typical DRMPr.

- The enforcement of existing and new dolomite-related by-laws is just as important as the by-laws themselves and care should be taken that they are implemented.

- Illegal building, or building without the permission and consent of the local authority on dolomite poses a problem that should be dealt with urgently and seriously. If left unattended, a lawless society may be created with a snowball effect with regards to all sorts of crime. All efforts must be made to prevent this from happening. One of the reasons is that communities may not have the funds to do the necessary assessments, designs or build houses according to relevant dolomite standards, and then rather choose to build without consent and take the law and some of the risk into their own hands. The availability of funds for these private home builders may alleviate the problem, as many may be willing to build according to the relevant standards if there are no extra costs involved. Another argument to consider is to diligently upgrade wet services of both the local authority and existing houses to relevant dolomite standards instead of spending money on drilling of site characterisation boreholes and expensive engineering design of small houses, which is in most cases not practical or feasible. In combination with good vigilance and commitment to risk management from the home owner or occupant as well as the local authority may keep in or even move areas towards a tolerable hazard level.

- Dolomite risk management necessitates the close cooperation, coordination and alignment among all de- 
partments in a local authority, which is often found to be a challenge. It may be necessary to make the relevant dolomite risk management actions part of the key performance indicators of staff members.

- A senior position for a dedicated, suitably qualified and experienced Dolomite Risk Manager with the necessary authority to implement a DRMPr across all departments, should be defined and formalised in government structures. This may be a separate unit or it may be within a Project Management Unit or any other relevant department, depending on the specific situation of each local authority. This person should be able to delegate actions between all departments. A supporting structure of personnel, as well as outsourced resources, should be considered.

- Capacity, institutional memory, knowledge, competency and the development of skills are key aspects for further attention.

- As development on dolomite is, in general, more expensive than normal development, and often only realised at a later stage in existing developments, funding is a major concern, especially in smaller local authorities and rural areas. The intervention and support of district, provincial and even national state authorities for additional funding should be pursued pro-actively.

- As state-owned land is becoming scarce, alternative land as well as alternative development types should be considered in future. Especially on dolomite, alternatives for typical RDP housing may prove to be more suitable on higher risk dolomite, and back-yard dwellings could become a stabilising factor if designed and constructed correctly in combination with primary buildings on residential stands.

- Ways to obtain buy-in on dolomite risk management from community leaders and ward councillors should continuously be prioritised. If the community perceives the leaders to be serious about risk management, they will most likely also be serious about it and therefore take up more responsibility, and vice versa.

- Upside opportunities should be identified and incorporated in new or further strategy development in order to help create a vision of hope in the community in an otherwise hopeless society. These opportunities are typically new and better standard of services, paved roads, well managed storm-water, bigger yards, stronger houses, better maintenance and a culture of trust and communication with the community which is then aware and empowered to manage its risk.

\subsection{Social}

- The perceptions that most vulnerable communities have about the role of government need to be understood. These perceptions also necessitate the understanding of different world views of different communities and individuals. These perceptions or world views may have to be challenged, or the DRMPr amended to take these into consideration, in order to successfully implement the DRMPr.

- A general lack of understanding of the risk associated with development on dolomite, due to no or limited information sharing, communication, understanding, training or education, necessitates a lot of energy and resources to be invested in changing this in future programmes. It is imperative that the affected community be fully aware of the risk associated with living on dolomite and that they share in the responsibility to manage the risk.

- There is a negative connotation to resettlement due to the invidious practices associated with the apartheid regime. Any future resettlement will have to take this reality into consideration in order to ensure that this challenge is overcome and that lives are not put at risk unduly.

- Many communities, but specifically the poor communities, can neither afford the required dolomite stability investigations nor the expensive rational designs and subsequent expensive construction for houses on high risk dolomite. Alternatives should be sought in order to provide these landowners with alternative land or financial assistance.

- Active dolomite risk management may become a catalyst for much-needed upgrading or supply of basic human needs such as adequate shelter, water, sanitation and food. Many households are merely surviving, leaving very little room for any capacity or willingness to adopt disaster risk management actions. If basic human needs are met, long-term economic growth and sustainability may develop, reducing the overall risk of a community because they are less vulnerable. A DRMPr may stimulate and necessitate bigger strategies for long-term township planning and development, such as City Development Strategies, opening up the possibility for regeneration programmes and therefore also funding for development and social upliftment. The political pain of dealing with the issues regarding the dolomite reality could thus be transformed to political gain over time. 


\section{Conclusions}

It is imperative that there should be a fine balance among the three pillars of sustainable development: environment, society and the economy. This should be the case for both new and existing communities with any development on dolomitic areas.

In order to ensure successful further integration and implementation of the DRMPr, both in the Tlokwe City Council and in other similar local authorities, some areas deemed to be most important were identified and broadly defined for attention and further research.

\section{References}

[1] Buttrick, D.B. (1986) Wad and Ferroan Soil Developed in the Dolomitic Area South of Pretoria. M.Sc. Dissertation, UP, Pretoria.

[2] Council for Geoscience (2010) Sinkholes and Subsidences. http://www.geoscience.org.za/index.php?option=com content\&task=view\&id=994\&Itemid=434

[3] Buttrick, D.B. and Van Schalkwyk, A. (1995) The Method of Scenario Supposition for Stability Evaluation of Sites on Dolomitic Land in South Africa. Journal of South African Institution of Civil Engineering, 37, 9-14.

[4] Waltham, T., Bell, F. and Culshaw, M. (2005) Sinkholes and Subsidence, Karst and Cavernous Rocks in Engineering and Construction. Praxis Publishing, UK.

[5] Ford, D.C. and Williams, P. (2007) Karst Hydrogeology and Geomorphology. 2nd Edition, Wiley. http://dx.doi.org/10.1002/9781118684986

[6] Council for Geoscience (2009) Dolomite Guideline: A Short Guide to Available Documents on Procedures for Developing Dolomitic Land. Council for Geoscience.

[7] AGES (2013) Tlokwe City Council: Dolomite Risk Management Strategy 2013: Report 1. Report Number: 2013/09/03 DRMS. AGES, Potchefstroom.

[8] South African National Standards (SANS) 1936 (2012) Development of Dolomite Land_Part 4: Risk Management. SABS Standards Division, Pretoria.

[9] South Africa (1996) Constitution of the Republic of South Africa, Act 108 of 1996.

[10] South Africa (2000) Municipal Systems Act 32 of 2000.

[11] South Africa (2002) Disaster Management Act 57 of 2002.

[12] AGES (2016) Dr Kenneth Kaunda District Municipality: Geo-Environmental Assessment of Dolomite Land. Report Number: 2015/06/10/GENV. AGES, Potchefstroom.

[13] AGES (2010) Dolomite Risk Management Programme: Report 5: Volume 2: Preliminary Regional Dolomite Risk Management Strategy and Plan for Potchefstroom: Framework for Report Number: 2010-05-03 DSA. AGES, Potchefstroom.

[14] Potgieter, A.S. (2012) The Development of a Dolomite Risk Management Strategy for the Tlokwe City Council. M.Sc. Dissertation, NWU, Potchefstroom.

[15] AGES (2010) Dolomite Risk Management Programme: Report 4: Volume 1: Geo-Environmental Assessment of Dolomitic Land in Potchefstroom in Preparation for the Development of a Dolomite Risk Management Plan. Report Number: 2010/05/03 DSA. AGES, Potchefstroom.

[16] Coetzee, C. and Van Niekerk, D. (2013) Towards a Disaster Risk Assessment Methodology for Communities Underlain by Dolomite. Disaster Prevention and Management, 22, 351-365. http://dx.doi.org/10.1108/DPM-04-2013-0068

[17] Buttrick, D.B., Trollip, N.Y.G., Gerber, A.A. and Pieterse, N.D. (2014) Susceptibility, Hazard Zonation and Risk Management: Quo Vadis. Proceedings of the Dolomite Seminar 2014, 25-26 June 2014, University of Pretoria.

[18] AGES (2013) Dolomite Risk Management Programme: Report 10: Integrated Dolomite Stability Investigation. Report Number: 2013/06/17 DSI. AGES, Potchefstroom.

[19] AGES (2013) Dolomite Risk Management Programme: Report 8: Regional Groundwater Model on the Dolomite Aquifer. Report Number: 2013/10/15 IWMS. AGES, Potchefstroom.

[20] FHP Consulting Engineers (2013) Risk Assessment of Impact of Internal Civil and Electrical Municipal Services on Dolomite Soils. FHP Consulting Engineers, Potchefstroom.

[21] AGES (2014) Dolomite Risk Management Programme: Report 2: Draft Dolomite Risk Management Plan 2013/2014. Report Number: 2013/10/01 DRMP. AGES, Potchefstroom.

[22] AGES (2016) Tlokwe Dolomite Risk Management Programme Phase C 2015/2016: On-Going Social Awareness. Report Number: 2016/03/01/SS. AGES, Potchefstroom. 